\title{
УДК 81'23
}

UDC 81'23

\author{
Плешков Евгений Сергеевич, Харченко Елена Владимировна \\ Южно-Уральский государственный университет (национальный исследователь- \\ ский университет) \\ г. Челябинск, Российская Федерация \\ Yevgenii S. Pleshkov, Elena V. Kharchenko \\ South Ural State University (National Research University) \\ Chelyabinsk, Russian Federation \\ evgeny-pl@mail.ru, ev-kharchenko@yandex.ru
}

\section{АНГЛОЯЗЫЧНЫЕ НАЗВАНИЯ ПЕСЕН: ПРОТЕСТ ИЛИ ПРИЗЫВ К ДЕЙСТВИЮ? ENGLISH SONG NAMES: PROTEST OR CALL FOR ACTION?}

\begin{abstract}
Аннотация
В статье рассматриваются аспекты влияния англоязычных названий песен, образованных в результате вторичной номинации из наименований наркотических веществ, на молодёжь. Ввиду большого количества и разнообразия наименований песен различных жанров авторы сочли необходимым ввести специальный термин «сонгонимы». В качестве материала исследования выбрано название песни LSD (исполнитель - рок-группа Hawkwind). Трудно однозначно предположить, какое влияние оказывают на слушателя названия песенного материала: призывают ли они к каким-либо действиям, или, наоборот, вызывают протест и отторжение. Поэтому в данном исследовании для авторов представлялось важным вербализовать образ названия песни LSD в языковом сознании молодых людей и выявить, какие посылы несёт в себе данное название - призывные или протестные. С помощью свободного ассоциативного эксперимента, по мнению авторов, «вскрываются» индивидуальные смыслы, вкладываемые индивидуумом в название песни. Эксперимент проводился среди студентов 2-4 курсов в одном из вузов г. Челябинска. Посредством построения ассоциативных полей было выявлено, что наименование песни LSD воспринимается молодыми людьми не как призыв к каким-либо действиям, а как некий протестный элемент отторжения.
\end{abstract}

\footnotetext{
Abstract

The article focuses upon some aspects of the impact of English song names resulting from secondary nomination from the names of narcotic substances on young subjects. A large number and variety of song names of different genres encouraged us to introduce a special term «songonyms». As the research material, the name of the song LSD (performed by the rock band Hawkwind) has been chosen. It is difficult to clearly assume what effect song names have on the listener: whether they call for any actions, or, on the contrary, cause a protest and rejection. Therefore, in this study, it seemed important to verbalize the image of the LSD song name in the linguistic consciousness of young people and to reveal what implications this name carries - calling for actions or protest. By means of free associative experiment, according to the authors, individual meanings inserted by an individual into the
} 
song name are "revealed". The experiment has been conducted among 2-4-year students in one of the universities of Chelyabinsk. Through the making up of associative fields, it has been revealed that the song name LSD is perceived by young people not as calling for any actions, but as a protest element of rejection.

Ключевые слова: имя собственное, название песни, языковое сознание, свободный ассоциативный эксперимент, рок-культура.

Keywords: proper name, song name, language consciousness, free associative experiment, rock culture.

doi: $10.22250 / 24107190 \_2019 \_5 \_2 \_139 \_149$

\section{1. Введение}

Ономастическое пространство любого языка представляет собой сложно организованную, динамическую, открытую систему, способную расширяться в результате появления новых объектов номинации. Не является исключением и ономастикон английского языка, составной частью которого выступают наименования песен. В современном мире существует большое количество музыкальных направлений, музыкальных групп и выпускаемых ими альбомов и, как следствие, бесчисленное множество названий песен. Но отдельного наименования для данной категории слов в науке не существует. В этой связи мы предлагаем для обозначения названий песен ввести специальный термин «сонгонимы» (от англ. song - песня) с целью расширения классификации имён собственных и удобства описания материала при выполнении научных исследований.

Имена собственные представляют собой совершенно особый пласт лексики и являются неотъемлемой частью современной жизни. По словам А. В. Суперанской, «имена собственные живо реагируют на все явления, происходящие в окружающей среде, в результате чего имена оказываются невольными регистраторами явлений природы и событий, имевших место в общественной жизни. Всё это фиксируется в именных основах» [Суперанская 2012, с. 36]. В именах отражаются социальные и культурные особенности жизни общества. В принципе, «мир, в котором мы живём, можно назвать миром имён и названий» [Горбаневский 1987, с. 6], поскольку каждый окружающий нас объект имеет или может иметь собственное имя.

Выше указанные утверждения справедливы и для названий песен, под которыми в данной работе мы понимаем наименования, относящиеся к сфере рок-музыки. Рок-музыка, в свою очередь, является частью молодёжной субкультуры.

Одной из актуальных проблем в ономастике в частности и в языкознании в целом является проблема изучения значения имени собственного, поскольку в науке до сих пор нет единой точки зрения по данному вопросу. Совокупность взглядов на проблему значения имени собственного можно отразить в трех основных позициях. Первая позиция заключается в том, 
что у имён собственных отрицается наличие как значения, так и понятия: «Имена собственные не заключают в себе ни понятия, ни значения. Они являются только различающим знаком» [Галкина-Федорук, 1956, с. 53]. Таким образом, с этой позиции функция имени собственного состоит в обеспечении простой номинации.

Вторая позиция, разделяемая Г. Суитом, Л. Витгенштейном, А. В. Суперанской и другими, основывается на том, что имя собственное может обрести значение, но только тогда, когда станет употребляться в речи, в специально подобранном речевом окружении и особой речевой ситуации. А. В. Суперанская пишет, что «ономастическая семантика совершенно особый тип семантики... В семантику имени входят и субъективные, социально обусловленные факторы и эмоции, которые референт вызывает у говорящего» [Суперанская, 2012, с. 323]. Субъективные факты и эмоции отражаются не в основном значении, а в коннотативном. Именно поэтому значение онима больше коннотативное. На это указывает и известный отечественный специалист в области ономастики Г. Ф. Ковалев, занимающийся исследованием имён собственных в художественных произведениях, подчёркивая, что оним имеет только два типа значения: коннотативное и этимологическое [Ковалев 2007, с. 20].

Третья позиция признает наличие у имени собственного и значения, и понятия. Так, О.Есперсен считал, что имя собственное «в каждом отдельном предложении ...имеет одно определённое значение, которое явствует из контекста и ситуации...» [Есперсен, 1958, с. 71]. Е. Курилович утверждал, что «в силу наличия у имени собственного семантического содержания, имя собственное обладает значением, а те объекты, которые оно способно обозначать, составляют сферу его употребления» [Курилович, 1962 , c. 251].

Ономастические единицы, по словам Г. Ф. Ковалева, обладают особой ценностью для человека, поэтому они требуют изучения не только в лингвистике, но и во многих других науках [Ковалев, 2017, с. 30]. Мы солидарны с мнением учёного и считаем, что имена собственные, вследствие размытости их семантики, как единицы, по словам А. А. Бурыкина, с «нереализованным смысловым потенциалом» [Бурыкин, 2010, с. 32] целесообразно изучать с позиций психолингвистики.

В настоящее время в рамках Московской психолингвистической школы проводятся исследования языкового сознания представителей различных культур. Под языковым сознанием, вслед за Е. Ф. Тарасовым, мы понимаем опосредованный языком образ мира той или иной культуры, т. е. «совокупность перцептивных, концептуальных и процедурных знаний носителя культуры об объектах реального мира» [Тарасов, 2000, с. 4]. Однако образы языкового сознания остаются скрытыми для исследователя до тех пор, пока не будут «овнешнены» (термин Е. Ф. Тарасова). Одним из способов овнешнения образов сознания является ассоциативный эксперимент, понимаемый как приём выявления ассоциаций, сложившихся у индивида в предшествующем опыте [Актуальные ..., 2016]. На наш взгляд, целесооб- 
разно осуществлять анализ имён собственных в контексте субкультуры с привлечением метода свободного ассоциативного эксперимента, позволяющего выявить специфику языкового сознания носителя той или иной субкультуры.

Актуальность описываемого в статье исследования заключается в том, что в настоящее время существует проблема изучения языкового сознания представителей так широко распространённых в современном мире различных субкультур и их знакового наполнения. Новизна работы определяется тем, что изучение специфики языкового сознания носителей молодёжной субкультуры на материале имён собственных не проводилось.

\section{2. Аспекты влияния рок-культуры на молодёжь}

Молодёжные субкультуры принято определять как протестные. Они противопоставляются общепринятой национальной культуре как имеющие собственную «систему норм и ценностей, отличающих группу от большинства обществ» [Лисовский, 1996, с. 332], как «своеобразный «сгусток» норм, идей, ценностей и идеалов в общем поле культуры» [Введение ..., 2001, с. 88].

Музыкальная субкультура, представителями которой являются в том числе и рок-музыканты, пытается донести свои идеи, ценности, идеалы до потребителя различными способами, выступающими в той или иной мере проявлениями протеста. В данной субкультуре можно рассматривать проявления протеста на нескольких уровнях: на уровне музыкальной продукции (собственно музыка и тексты песен); на уровне организации сообщества: визуально-символическом (отражённом во внешнем виде членов субкультуры), языковом, предполагающем наличие более или менее развитого пласта собственного сленга, и т. п.; на поведенческом уровне [Аминова, 2014, с. 276]. Для нас особый интерес представляет первый из указанных уровней, в котором, на наш взгляд, следует учитывать не только тексты песен, но, прежде всего, их названия. Поскольку зачастую именно с названия начинается восприятие песни потребителем, это наименование уже может содержать в себе некий протест либо призыв к действию.

История развития рок-музыки как части общей сферы музыкального производства свидетельствует о тесной связи этого направления с социальными процессами, происходящими в обществе. Возникнув как протест против унифицированной развлекательной поп-музыки, рок превращается в мощное социальное движение, выступающее против негативных явлений в обществе, в частности, таких, как алкоголизм и наркомания. Социальный протест, преподнесённый в нестандартной музыкальной форме, а также массовость и зрелищность этого музыкального направления привлекают в рок-культуру значительную часть современной молодёжи, влияя на формирование её ценностных установок и социальной позиции [Громаков, 2014, с. 115]. Именно поэтому представляется важным исследование всех продуктов рок-культуры, начиная с названий и текстов песен и заканчивая поведением рок-музыкантов. 
Рок-культура в целом и рок-музыка в частности более социально ориентированы по сравнению с другими субкультурами и музыкальными направлениями, отражая процессы, которые происходят в обществе и в молодёжной среде, тем самым потенциально являясь и ресурсом, и риском формирования про- или асоциальных граждан [Громаков 2014, с. 117].

Не существует однозначного мнения о влиянии современной рок-музыки и её составляющих (тексты песен, названия песен) на молодёжь. Ни для кого не секрет, что в продуктах рок-культуры зачастую воспеваются темы смерти, суицида, употребления высокоактивных веществ и т. д. В частности, в творчестве музыкальной рок-группы Marilyn Manson звучит тема смерти (например, песни "King Kill 33"" (с англ. «Король Убийство 33»), "President Dead" (с англ. «Президент мёртв»). Потребители не всегда воспринимают посылы, содержащиеся в продуктах рок-музыки, как протестные. Они могут восприниматься и как призывные, особенно в молодёжной среде. Так, например, в 1999 году в школе «Колумбайн» в США подростки Эрик Харрис и Дилан Клиболд совершили массовое убийство. После этого общественность обвинила Мэрилина Мэнсона в пропаганде агрессии и насилия, а также суицидов и сатанизма по причине того, что эти подростки являлись фанатами группы Marilyn Manson. Тема наркотиков также широко представлена в творчестве рок-музыкантов, в том числе и в названиях песен. Приведём следующие примеры: Cocaine - песня Nazareth, LSD - песня Hawkwind, Sincemilla (ямайская разновидность анаши) - песня Black Uhuru, Morphium - песня Carlos Peron, Heroin - песня Velvet Underground и др.

Здесь нетрудно заметить, что данные названия образованы в результате процесса вторичной номинации, а их мотивирующими основами являются названия химических веществ. В данной ситуации имеет место случай, когда имя собственное материально совпадает с именем нарицательным, что можно рассматривать как случай омонимии имён собственных [Бурыкин, 2010, с. 29]. Возможна и несколько иная ситуация, когда одно уникальное имя прикладывается к множеству объектов. В частности, А. А. Бурыкин приводит следующий пример: Москва - это не только название столицы России, это еще и название гостиниц в Москве и ЛенинградеСанкт-Петербурге, это название пишущей машинки, название бассейна, находившегося некогда на месте Храма Христа Спасителя, название футбольного клуба, существовавшего в Москве до 2008 года, название ледокола [Бурыкин, 2010, с.27]. Такие примеры можно рассматривать как явление полисемии онимов. Полисемия наблюдается и в именах собственных, образованных на основе названий химических веществ. Так, Morphium - это не только название песни Carlos Peron, но также и название испанской музыкальной группы. Следует отметить, что зачастую дифференцировать явления омонимии и полисемии онимов представляется трудной задачей, поэтому данная проблема является важной в русле проблем изучения значения имени собственного.

Что касается связи рок-музыки и наркотических веществ, то есть мнение, что между рок-музыкой и наркотиками существует определенная связь. В частности, пропагандировал наркотические вещества писатель Кен 
Кизи в известном романе «Полет над гнездом кукушки» (1962 г.) и раздавал LSD (один из сильнейших наркотиков, активно действующих на сознание) всем зрителям на концертах с участием рок-музыкантов [Володихин, 2002, c. 52-60]. Как правило, зрителями подобных мероприятий являются молодые люди, психика которых очень лабильна, и стимулирование подобными «подарками» может привести к деструктивным последствиям.

Трудно однозначно предположить, какое влияние оказывают на потребителя (слушателя) названия песенного материала: призывают ли они к каким-либо действиям, или, наоборот, вызывают протест. В современных условиях, в век Интернета и развития информационных технологий молодые люди предпочитают прослушивать музыкальные композиции в социальных сетях. Открывая плейлист, первое, что они видят, - это названия группы (исполнителя) и песни. То есть ещё до прослушивания песни у них в сознании складывается некий образ, конструируемый на основе наименования песенного материала. Некоторые названия привлекают внимание, а другие - отталкивают. К примеру, если в наименовании присутствуют темы смерти или наркотиков, а слушатель является фанатом рок-музыки либо фанатом конкретной группы, авторитетной для него, или он просто получает удовольствие от прослушивания, то посылы, содержащиеся в названии, возможно, будут восприниматься как «хорошие» и «правильные».

Однако смыслы, вкладываемые в наименование песни, для каждого будут индивидуальными. Как отмечает А. В. Суперанская, смыслы имени собственного проявляются на уровне речи в виде комплекса субъективных сведений и эмоциональных обертонов, индивидуальных для каждого носителя языка [Суперанская, 2012, с. 322-323]. Одним из способов «вскрытия» индивидуальных смыслов имени собственного выступает свободный ассоциативный эксперимент, с помощью которого целесообразно осуществлять анализ названий песен.

Реакция в условиях свободного ассоциативного эксперимента является «неспровоцированной», действительно свободной, что позволяет интерпретировать её как вербальную актуализацию некоторого семантического компонента слова-стимула, рассматриваемого испытуемым как наиболее яркий, значимый и важный для его языкового сознания [Виноградова, Стернин, 2016, с. 47].

\section{3. Эксперимент}

\section{1. Материал исследования}

В качестве материала исследования мы выбрали название песни «LSD» (группа Hawkwind). Данное наименование образовано в результате вторичной номинации из химического термина и его мотивирующей основой является апеллятив lysergic acid diethylamide (диэтиламид лизергиновой кислоты) - сильное психоактивное вещество.

Нами был проведён свободный ассоциативный эксперимент в декабре 2018 года среди студентов 2-4 курсов (50 респондентов), обучающихся по направлению «Химия» в Южно-Уральском государственном универси- 
тете (г. Челябинск). Возраст респондентов как представителей молодёжной субкультуры укладывался в предел от 18 до 24 лет. Гендерный состав группы респондентов характеризовался следующим образом: по 50\% респондентов мужского и женского пола. Цель эксперимента состояла в вербализации образа названия песни «LSD» в языковом сознании студентов. Для нас также представлялось важным выявить, какие посылы несёт в себе данное название - призывные или протестные.

Построение ассоциативного поля (далее - АП) слова-стимула $L S D$ позволило выявить образы языкового сознания студентов. Рассмотрим тенденции, которые мы обнаружили в процессе проведения анализа.

\section{2. Обсуждение результатов}

Обратимся к содержанию АП слова-стимула LSD. Ядро составленного нами АП представлено следующими реакциями: наркотик (5), веселье (4), галлюцинации (4), зависимость (3). Полученные ассоциаты иллюстрируют две семантические зоны: «LSD как наркотик» и «последствия приёма LSD». Причём последнюю зону можно условно разбить на два подуровня - «положительные последствия» (веселье) и «отрицательные последствия» (галлюиинации, зависимость).

Итак, ассоциаты ядерной зоны (наиболее частотные реакции) вербализуют в большинстве своём негативное отношение респондентов, то есть его актуализацию в сознании можно охарактеризовать как «протестную».

Анализ периферии (менее частотные реакции) АП показал следующую картину: клуб (2), синтез (2), таблетки (2), фильм (2), яркость (2), бумажка, велосипед, вред, группа, дорого, запрещён, кайф, колесо, краски, круто, человек, мультик, мы такое не купим, опасность, пакетик, песня, сильный, сложно найти, смерть, СПИД, туман, увечья, Хофманн, эксперимент (единичные реакции). Как видим, периферия представлена богатым набором реакций по сравнению с ядерной зоной и имеет важное значение для полноценного анализа образов языкового сознания. Поэтому при анализе АП необходимо учитывать все ассоциаты независимо от их частотности. В периферийной зоне АП чётко прослеживаются несколько семантических зон:

1) «формы и способы приёма LSD»: таблетки, бумажка, колесо ['таблетка' в сленге наркоманов], пакетик;

2) «характеристики и свойства»: дорого, запрещён, круто, сильныгй, сложно найти, мы такое не купим;

3) «последствия приёма LSD» - зона, которая выражена более ярко по сравнению с аналогичной зоной в ядре: яркость, кайф, краски, круто «положительные последствия», вред, опасность, смерть, СПИД, туман, увечья - «отрицательные последствия»;

4) «получение LSD»-велосипед, синтез, Хофманн, эксперимент, где представлены реакции, значимые с точки зрения будущего специалиста-химика и обусловленные процессом формирования профессионального языкового сознания.

Особенно интересной, на наш взгляд, здесь является ситуация, когда на имя собственное (название песни «LSD») даётся реакция в виде другого 
имени собственного - антропонима Хофманн (Альберт Хофманн - швейцарский химик, «отец» ЛСД). Ещё одной интересной особенностью выступает реакция велосипед, которая также связана с именем А. Хофманна («День велосипеда» 19 апреля 1943 года, когда А. Хофманн преднамеренно, первым из людей, принял внутрь ЛСД). Полученные ассоциаты свидетельствуют о том, что респонденты не понаслышке знакомы с ЛСД и проявляют к нему интерес. Отдельно можно выделить реакции клуб, которую можно рассматривать как место употребления или покупки наркотика, что не является редкостью в молодежной среде, и человек - создатель, потребитель, продавец. Вызывают опасение такие ассоциаты, как кайф и круто, отражающие положительные коннотации в процессе ассоциирования, поскольку они наталкивают на мысль о том, что часть респондентов имели подобный опыт. Сходным же образом можно охарактеризовать ассоциаты сильный, дорого, сложно найти. Ассоциат мы такое не купим, наоборот, свидетельствует об отрицательном отношении. Также следует отметить реакции фильм и мультик, которые можно объяснить знакомством студентов с так называемыми психоделическими видеопродуктами, т. е. созданными людьми, находящимися под действием наркотических веществ. Интересно, что только $4 \%$ респондентов идентифицировали название «LSD» как песню или группу. Этот факт, возможно, указывает на то, что данное наименование актуализируется в сознании не как имя собственное, а именно как наркотическое вещество с соответствующими характеристиками, что может быть обусловлено влиянием профессионального языкового сознания.

Итак, ассоциаты периферийной зоны вербализуют в большей степени негативные коннотации при предъявлении стимула LSD, что наблюдалось и в ядерной зоне. То есть посыл, содержащийся в данном наименовании, вербализуется в языковом сознании респондентов как «протестный».

\section{4. Заключение}

Проведённое исследование позволяет сделать ряд выводов. Во-первых, введение в научный оборот термина «сонгоним» представляется полезным и вносит определённый вклад в теорию ономастики, которая охватывает всё больше областей деятельности человека. В языковой составляющей рок-культуры как одного из наиболее социально-ориентированных направлений бунтарского характера сонгонимы, несомненно, занимают важное место. Многие из них представляют собой диалектическое единство протеста-призыва, вскрывая острые противоречия различных аспектов антисоциального поведения, включая наркоманию, захлестнувшую мир. Нельзя не заинтересоваться тем, какое отражение в языковом сознании людей разного возраста, уровня образования, профессий и так далее имеют соответствующие онимы.

При помощи психолингвистических методов, а именно ассоциативного эксперимента, было выяснено, какое отражение находит сонгоним LSD в языковом сознании студентов-химиков. Результаты исследования показали, что наименование песни «LSD» было воспринято участниками 
эксперимента не как призыв к каким-либо действиям, а как некий протестный элемент отторжения, поскольку и в ядерной, и в периферийной зонах преобладающей ассоциацией оказалась «наркотик, вызывающий галлюцинации и зависимость, наносящий вред здоровью и могущий привести к смерти». Тем не менее, не стоит сбрасывать со счетов и положительные коннотации данного слова-стимула, присутствующие как в ядерной, так и в периферийной зонах. Считаем, что в конкретной ситуации восприятие названия песни и конструирование образа будет зависеть от индивидуальных особенностей психотипа человека и, вероятно, его возраста. Профессиональное языковое сознание также может сыграть определённую роль: не исключено, что у респондентов-филологов, журналистов, музыкантов и так далее, распределение зон оказалось бы несколько другим. Выяснение этого и ряда других моментов составит перспективу настоящего исследования.

\section{Список литературы}

1. Актуальные проблемы проведения и интерпретации результатов психолингвистических экспериментов [Текст] / Н. В. Уфимцева, А. В. Рудакова, И. А. Стернин, М. Дебренн, Л. О. Бутакова // Психолингвистика и лексикография: сб. науч. тр. - Вып. 3 / науч. ред. А. В. Рудакова. - Воронеж : Истоки, 2016. - С. 4-19.

2. Аминова, В. А. Протест в субкультуре металлистов [Текст] / В. А. Аминова // Ярославский педагогический вестник. - 2014. - № 2. - С. 275-279.

3. Бурыкин, А. А. Проблемы полисемии и омонимии в ономастике [Текст] / А. А. Бурыкин // Ономастика и общество: язык и культура. Материалы Первой Всероссийской научной конференции (14-15 октября 2010 года). - Тамбов, 2010. - C. 25-35.

4. Виноградова, О.Е. Психолингвистические методы в описании семантики слова [Текст] / О. Е. Виноградова, И. А. Стернин. - Воронеж : Истоки, 2016. - 160 с.

5. Володихин, Д. М. Музыка наших дней: современная энциклопедия [Текст] / Д. М. Володихин. - М. : Аванта-плюс, 2002. - 432 с.

6. Галкина-Федорук, Е. М. Слово и понятие [Текст] / Е. М. Галкина-Федорук. М. : Учпедгиз, 1956. - 54 с.

7. Горбаневский, М. В. В мире имен и названий [Текст] / М. В. Горбаневский. М.: Знание, 1987. - 208 с.

8. Громаков, А. И. Рок-музыка как кейс музыкальной социализации [Текст] / А. И. Громаков // Теория и практика общественного развития. - 2014. - № 1. С. $115-117$.

9. Введение в социологию искусства [Текст] / Е.В. Дуков, В.С.Жидков, Ю. В. Осокин, К. Б. Соколов, Н. А. Хренов. - СПб : Алетейя, 2001. - 256 с.

10. Есперсен, О. Философия грамматики: пер. с англ. [Текст] / О. Есперсен. - М. : Издательство иностранной литературы, 1958. - 400 с.

11. Ковалев, Г. Ф. Аспекты изучения имен собственных в художественных произведениях [Текст] / Г. Ф. Ковалев // I Крымские Международные Михайловские чтения «Собственное имя в русской и мировой литературе». - Крым - Донбасс, 2007. - C. 19-23. 
12. Ковалев, Г. Ф. Литературная ономастика - поле исследований для литературоведов и лингвистов [Текст] / Г. Ф. Ковалев // Русистика без границ. - 2017. Т. 1. - № 2 (2). - С. 30-40.

13. Курилович, Е. Положение имени собственного в языке [Текст] / Е. Курилович // Очерки по лингвистике: сб. статей. - М. : Изд-во иностранной литературы, 1962. - С. 251-256.

14. Лисовский, В. Т. Социология молодежи [Текст] / В. Т. Лисовский. - СПб., 1996. $-460 \mathrm{c}$.

15. Суперанская, А. В. Общая теория имени собственного [Текст] / А. В. Суперанская. - М. : Книжный дом «ЛИБРОКОМ», 2012. - 368 с.

16. Тарасов, Е.Ф. Языковое сознание - перспективы исследования [Текст] / Е. Ф. Тарасов // Языковое сознание: содержание и функционирование: XIII Международный симпозиум по психолингвистике и теории коммуникации. М. : Институт языкознания РАН, 2000. - С. 2-3.

\section{References}

1. Ufimtseva, N. V., Rudakova, A. V., Sternin, I. A., $\quad$ Debrenn, M., Butakova, L. O. (2016). Aktual'nye problemy provedeniya i interpretatsii resul'tatov psikholingvisticheskikh experimentov [Current issues of performing psycholinguistic experiments and interpreting their data]. In A. V. Rudakova, Psikholingvistika $i$ leksikografiya [Psycholinguistics and lexicography]: A collection of scientific papers (Vol. 3, 4-19). Voronezh : Istoki Press.

2. Aminova, V. A. (2014). Protest v subkul'ture metallistov [Protest in a heavy metal subculture]. Yaroslavskiy pedagogicheskiy vestnik [Yaroslavl Pedagogical Bullein], 2, 275-279.

3. Burykin, A. A. (2010). Problemy polisemii i omonimii v onomastike [Issues of polysemy and homonymy in onomatology]. Onomastika i obshchestvo: yazyk I kul'tura [Onomatology and society: Language and culture]. Proc. First All-Russia Scientific Conference, October 14-15, 2010 (pp. 25-35). Tambov.

4. Vinogradova, O. E., Sternin, I. A. (2016). Psikholingvisticheskie metody v opisanii semantiki slova [Psycholinguistic methods in the description of the semantics of the word]. Voronezh.

5. Volodikhin, D. (2002). Muzyka nashikh dney: sovremennaya entsiklopediya [Music today: A modern encyclopedia]. Moscow.

6. Galkina-Fedoruk, E. M. (1956). Slovo i ponyatie [Word and concept]. Moscow.

7. Gorbanevskiy, M. V. (1987). V mire imen i nazvaniy [In the world of names]. Moscow.

8. Gromakov, A. I. (2014). Rok-muzyka kak keys muzykal'noy sotsializatsii [Rock music as a case of musical socialization]. Teoriya i praktika obshchestvennogo razvitiya [Theory and Practice of Social Development], 1, 115-117.

9. Dukov, E. V., Zhidkov, V. S., Osokin, Yu. V., Sokolov, K. B., Khrenov, N. A. (2001). Vvedenie $\mathrm{v}$ sotsiologiyu iskusstva [Introduction into the sociology of art]. Saint Petersburg.

10. Espersen, O. (1958). Filosofiya grammatiki [The philosophy of grammar]. Moscow. 
11. Kovalev, G. F. (2007). Aspekty izucheniya imen sobstvennykh v khudozhestvennykh proizvedeniyakh [The problem of studying nomina propria in belleslettres]. I Krymskie Mezhdunarodnye Mikhaylovskie chteniya «Sobstvennoe imya v russkoy i mirovoy literature» [The First International Mikhaylovskie Readings in Crimea] (pp. 19-23). Crimea ; Donbass.

12. Kovalev, G. F. (2017). Literaturnaya onomastika - pole issledovaniy dlya literaturovedov i lingvistov [Literary Onomastics - General Field Research for Specialists in Literature and Linguistics]. Rusistika bez granits [Russian Studies without Borders], 1, 2 (2), 30-40.

13. Kurilovich, E. (1962). Polozhenie imeni sobstvennogo v yazyke [The position of a proper name in the language]. Ocherki po lingvistike [Categories: Linguistics] (pp. 251-256). Moscow.

14. Lisovskiy, V. T. (1996). Sotsiologiya molodezhi [Sociology of youth]. Saint Petersburg.

15. Superanskaya, A. V. (2012). Obshchaya teoriya imeni sobstvennogo [The general theory of a proper name]. Moscow.

16. Tarasov, E. F. (2000). Yazykovoe soznanie - perspektivy issledovaniya [Language consciousness - outlook for research]. Yazykovoe soznanie: soderzhanie $i$ funktsionirovanie [Language consciousness: Content and functioning]: XIII International Symposium in Psycholinguistics and the Theory of Communication. Moscow : Institute for Language Studies of Russian Academy of Sciences, 2000. C. 2-3. 